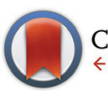

CrossMark \&lick for updates

Cite this: Polym. Chem., 2014, 5 , 6593

Received 13th May 2014, Accepted 27th July 2014

DOI: 10.1039/c4py00670d

www.rsc.org/polymers

\section{Diazo transfer at polydopamine - a new way to functionalization $\uparrow$}

\author{
R. Mrówczyński, ${ }^{a, b, c}$ L. Magerusan, ${ }^{a}$ R. Turcu ${ }^{a}$ and J. Liebscher ${ }^{\star a, b}$
}

The possibility of introducing azido functions onto polydopamine by diazo transfer making use of existing aminoethyl moieties was verified at polydopamine-coated magnetite nanoparticles. The resulting azidofunctionalized $\mathrm{Fe}_{3} \mathrm{O}_{4}$ apolydopamine nanoparticles serve as a magnetic nano-platform for the introduction of interesting applicatory functions by click-chemistry (CUAAC) as exemplified by linking biotin, tetraacetylglucose, dansyl and proline.

\section{Introduction}

Nanotechnology has grown rapidly in recent years. ${ }^{1-3}$ Magnetic nanoparticles (MNP) are among the pillars of this field. ${ }^{4}$ They have been widely used in medicine, ${ }^{5}$ as drug delivery systems ${ }^{6,7}$ resonance imaging, ${ }^{8}$ and as support for metal catalysts and organocatalysts. ${ }^{9-11}$ Different coating agents have been used for covering $\mathrm{MNP},{ }^{12,13}$ for example polymers like dextrane,${ }^{14}$ polyvinyl alcohol, ${ }^{15}$ polypyrrole,${ }^{16}$ polyacrylates ${ }^{17}$ and others. ${ }^{18}$ Non-polymeric agents like carboxylic acids are also suitable. ${ }^{19}$ The coating can allow surface engineering of MNP either by direct introduction of functionalities or reactive groups for further reactions. In the latter case amino, azido, isothiocyanate and carboxylic groups are common.

Azido groups have gained increasing interest because they can undergo copper-catalyzed azide alkyne cycloaddition (CuAAC). This reaction tolerates most functional groups and the resulting 1,2,3-triazoles are robust linkers. Thus, azido groups are powerful tools also for chemoselective ${ }^{20}$ and orthogonal functionalization of MNP. ${ }^{21-23}$

One of the methods for introducing the azido moiety onto MNP is the diazo transfer reaction to amino groups. ${ }^{24}$ This reaction was applied for membrane modification. ${ }^{25}$ It was also utilized in the preparation of trifunctional magnetic nanoparti-

\footnotetext{
${ }^{a}$ National Institute of Research and Development for Isotopic and Molecular Technologies (INCDTIM), Str. Donath 65-103, RO-400293 Cluj-Napoca, Romania. E-mail: liebscher@chemie.hu-berlin.de

${ }^{b}$ Department of Chemistry, Humboldt-University Berlin, Brook-Taylor-Str. 2, 12489 Berlin, Germany

${ }^{c}$ NanoBioMedical Centre, Adam Mickiewicz University, Umultowska 85, 61-614 Poznan, Poland

$\dagger$ Electronic supplementary information (ESI) available: TGA of MNP 2 and $\mathbf{4 b}$ See DOI: $10.1039 / \mathrm{c} 4 \mathrm{py} 00670 \mathrm{~d}$
}

cles, one of the key synthetic steps for linking a myriad of (bio)macromolecules. ${ }^{20}$

Lately, polydopamine (PDA) has been introduced as versatile polymer coating. ${ }^{26,27}$ This nature-inspired polymer was developed by Messersmith in $2007 .^{28}$ It has been shown that PDA could cover various materials like noble metals $(\mathrm{Au}, \mathrm{Ag}$, $\mathrm{Pt}, \mathrm{Pd}$ ), $\mathrm{SiO}_{2}, \mathrm{Al}_{2} \mathrm{O}_{3}$ and polymers (polystyrene, polyethylene, polycarbonate, polyethylene terephthalate, polytetrafluoroethylene) in basic solution resulting in strongly adherent layers. A variety of nanoparticles, including magnetic nanoparticles, have been coated with PDA. Polydopamine-coatings are considered to be non-poisonous and biocompatible and have found various biomedical applications ${ }^{29-35}$, such as in drug transport and delivery, as antibacterial coatings, in separations of biological materials or poisonous contaminants ${ }^{36,37}$ and as supports for metal ${ }^{29}$ and organocatalytic moieties. ${ }^{38}$ PDA coatings also served as media for fixing various biomolecules or enzymes. ${ }^{39,40}$ Here, the occurrence of carbonyl and Michael-acceptor moieties is exploited enabling reaction with amines or thiols as nucleophiles. In order to extend the scope of functionalization of PDA other reactive groups have to be introduced. Recently, we presented the introduction of azido groups into PDA by reaction with 4-azidobutylamine enabling CuAAC for further functionalization. ${ }^{38}$ Taking into account a recent report that PDA contains aminoethyl groups ${ }^{41}$ it appeared challenging to exploit the hitherto ignored amine reactivity rather than the carbonyl or Michel-acceptor reactivity.

Here, we disclose diazo transfer reaction performed directly at PDA coated MNP. As a result, a new magnetic azido nanoplatform with robust PDA coating is obtained. The chemical reactivity of the appearing azido functionalities was verified by subsequent CuAAC reactions with different important biological units like biotin (a recognition function), galactose (interest 
in cancer therapy), dansyl (fluorescent marker) and proline (organocatalyst).

\section{Experimental part}

The morphology of functionalized magnetic nanoparticles was determined by TEM using a 1010 JEOL transmission electron microscope. The mean diameter was obtained from the fitting of diameter histograms with a log-normal distribution function as given by the following equation:

$$
f(D)=\frac{1}{D \sigma \sqrt{2 \pi}} \exp \left[-\frac{1}{2}\left(\frac{\ln ^{2} D / D_{0}}{\sigma^{2}}\right)\right]
$$

where $D$ is the diameter, $D_{0}$ is the mean diameter and $\sigma$ is the standard deviation.

FT-IR spectra were measured on a JASCO FTIR 610 spectrophotometer. The magnetic measurements were performed at room temperature using a Vibrating Sample Magnetometer, Cryogenics.

The chemical surface analysis for the functionalized magnetic nanoparticles was performed by X-ray Photoelectron Spectroscopy (XPS) using a XPS spectrometer SPECS equipped with a dual-anode X-ray source $\mathrm{Al} / \mathrm{Mg}$, a PHOIBOS 150 2D CCD hemispherical energy analyzer and a multi-channeltron detector with vacuum maintained at $1 \times 10^{-9}$ torr. The $\mathrm{AlK}_{\mathrm{K} \alpha} \mathrm{X}$-ray source $(1486.6 \mathrm{eV})$ operated at $200 \mathrm{~W}$ was used for XPS investigations. The XPS survey spectra were recorded at $30 \mathrm{eV}$ pass energy, $0.5 \mathrm{eV}$ per step. The high resolution spectra for individual elements were recorded by accumulating 10-15 scans at $30 \mathrm{eV}$ pass energy and $0.1 \mathrm{eV}$ per step. The samples were applied as colloidal suspensions in methanol and dried in successive layers on an indium foil stacked on a Wolfram sample holder. The surface cleaning was performed by argon ion bombardment at $300 \mathrm{~V}$ for 3 minutes. Data analysis and curve fitting were performed using Casa XPS software with a GaussianLorentzian product function and a non-linear Shirley background subtraction. Dynamic light scattering (DLS) measurements were carried out with a Brookhaven Instrument Corp. goniometer and a light scattering system. Acquisition time was set at 90 seconds, a laser radiation wavelength of $632.8 \mathrm{~nm}$ was used and the angle for data acquisition was $90^{\circ}$.

Magnetic nanoparticles covered with a chemisorbed oleic acid monolayer were obtained from the group of Prof. Dr Ladislau Vekas, Romanian Academy - Timisoara branch.

\section{Synthesis of MNP 2}

MNP 1 (1.33 g) were dispersed in $\mathrm{H}_{2} \mathrm{O}(2.66 \mathrm{ml})$ followed by addition of $\mathrm{NaHCO}_{3}(0.717 \mathrm{~g}, 8.5 \mathrm{mmol}) . \mathrm{CuSO}_{4} \cdot 5 \mathrm{H}_{2} \mathrm{O}(21 \mathrm{mg}$, $10 \mathrm{~mol} \%$ ) and $\mathrm{TfN}_{3}$ solution (4.5 ml, $2 \mathrm{M} \mathrm{MeOH}-\mathrm{PhMe}-\mathrm{H}_{2} \mathrm{O}$ mixture) were added. Stirring was continued at RT for $20 \mathrm{~h}$. MNP 2 were collected by an external magnet and washed with $\mathrm{MeOH}(2 \times 100 \mathrm{ml})$ and $\mathrm{Et}_{2} \mathrm{O}(2 \times 50 \mathrm{ml})$. After drying MNP 2 were obtained as black powder.

\section{Synthesis of MNP 4}

In a typical experiment MNP $2(0.22 \mathrm{~g})$ were dispersed in $\mathrm{MeOH}(10 \mathrm{ml})$ followed by addition of alkyne $3(0.5 \mathrm{mmol})$. $\mathrm{CuSO}_{4} \cdot 5 \mathrm{H}_{2} \mathrm{O}$ (25 mg, $20 \mathrm{~mol} \%$ ) and sodium ascorbate (40 mg, $40 \mathrm{~mol} \%$ ) were added under stirring. The mixture was stirred at RT for $20 \mathrm{~h}$. After collecting by an external magnet, washing with $\mathrm{MeOH}(3 \times 100 \mathrm{ml})$ and drying the MNP 4 were obtained as black powder.

\section{Results and discussion}

Magnetic nanoparticles 1 coated with PDA were prepared according to a literature protocol. ${ }^{38}$ The diazo transfer reaction was performed similarly to a reported procedure ${ }^{42}$ in a heterogeneous phase, with a $\mathrm{TfN}_{3}$ solution in the presence of $\mathrm{NaHCO}_{3}$ and $\mathrm{CuSO}_{4} \cdot 5 \mathrm{H}_{2} \mathrm{O}$ as the catalyst. The resulting MNP 2 were magnetically separated. The morphology of the particles 2 was determined by TEM revealing well separated, nicely dispersed nanoparticles with spherical shape and a medium size of about $16 \mathrm{~nm}$ (Fig. 1). They exhibit a peak at $2107 \mathrm{~cm}^{-1}$ in the FTIR-spectrum typical for azido moieties (Fig. 2). This proved that diazo transfer reaction at MNP 1 was successful and provided new azido modified PDA coated nanoparticles 2 as a potentially magnetic nanoplatform for CuAAC with alkyne partners.

According to DLS-measurements the hydrodynamic diameter amounts to $340.7 \mathrm{~nm}$ in methanol (Fig. 6). As can be seen by the lack of a hysteresis loop in the magnetic measurement (Fig. 5) MNP 2 are superparamagnetic with a high value of saturation magnetisation $M_{\mathrm{s}}=52 \mathrm{emu} \mathrm{g}^{-1}$.

With these novel magnetic nanoplatforms 2 in hand we checked their versatility to attach bio-entities via CuAAC reaction in some selected examples. CuAAC was performed with propargyl derivatives of biotin $\mathbf{3 a}$, tetraacetylgalactose $\mathbf{3 b}$, dansyl 3c and proline 3d (Scheme 1) in $\mathrm{MeOH}$ using $\mathrm{CuSO}_{4}{ }^{-}$ $\mathrm{Na}$-ascorbate as the catalytic system. FTIR spectra of the resulting MNP 4 revealed a decrease of the intensity of the azide peak as compared with the precursors 2 confirming a successful transformation of azido moieties into triazoles as a result

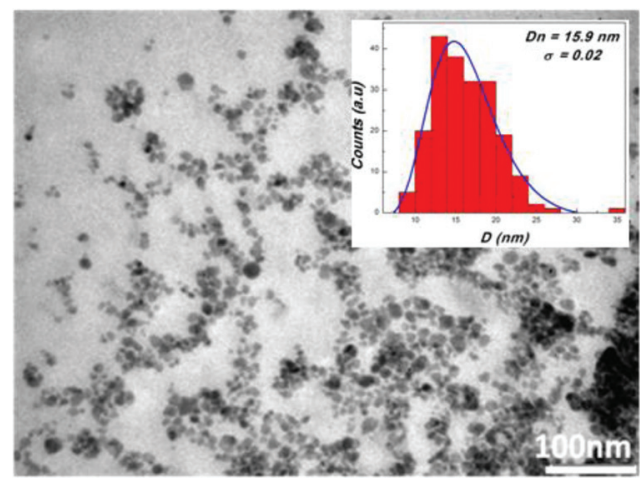

Fig. 1 TEM image of MNP 2. 

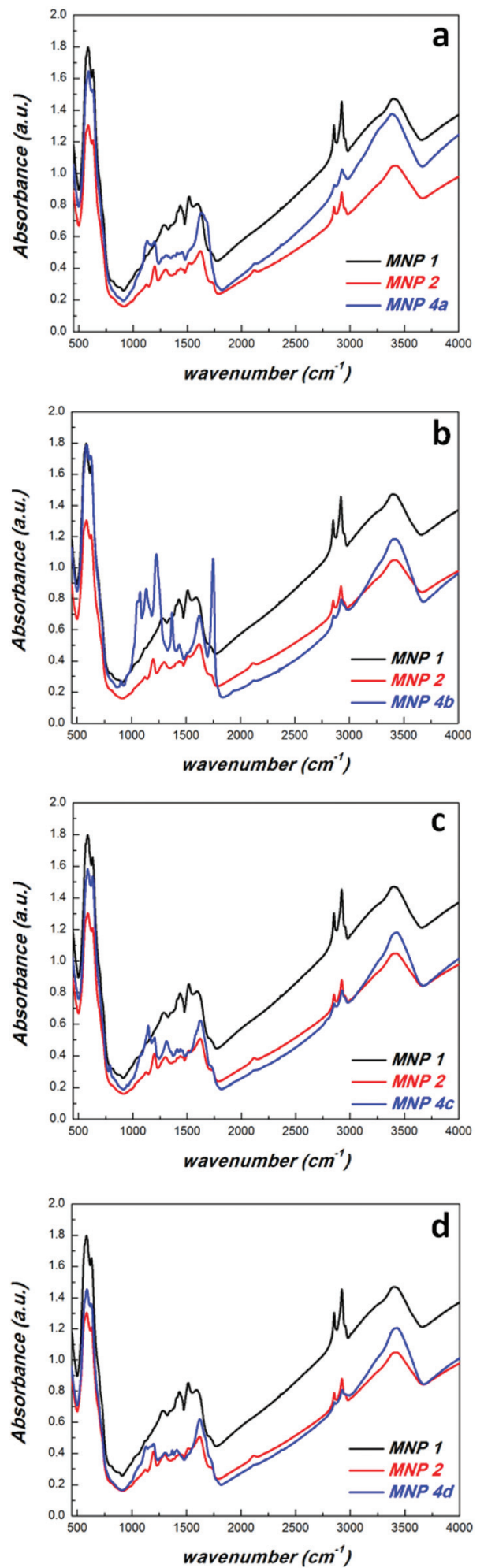

Fig. 2 FTIR-spectra of MNP 1, 2 and 4a (a), 4b (b), 4c (c), 4d (d).

of the CuAAC. Obviously, some of the azido groups of MNP 2 were not accessible by the CuAAC explaining the fact that the azido IR-band did not fully disappear. A similar effect was observed in CuAAC reactions of PDA-coated MNP. ${ }^{38}$ Anyway,

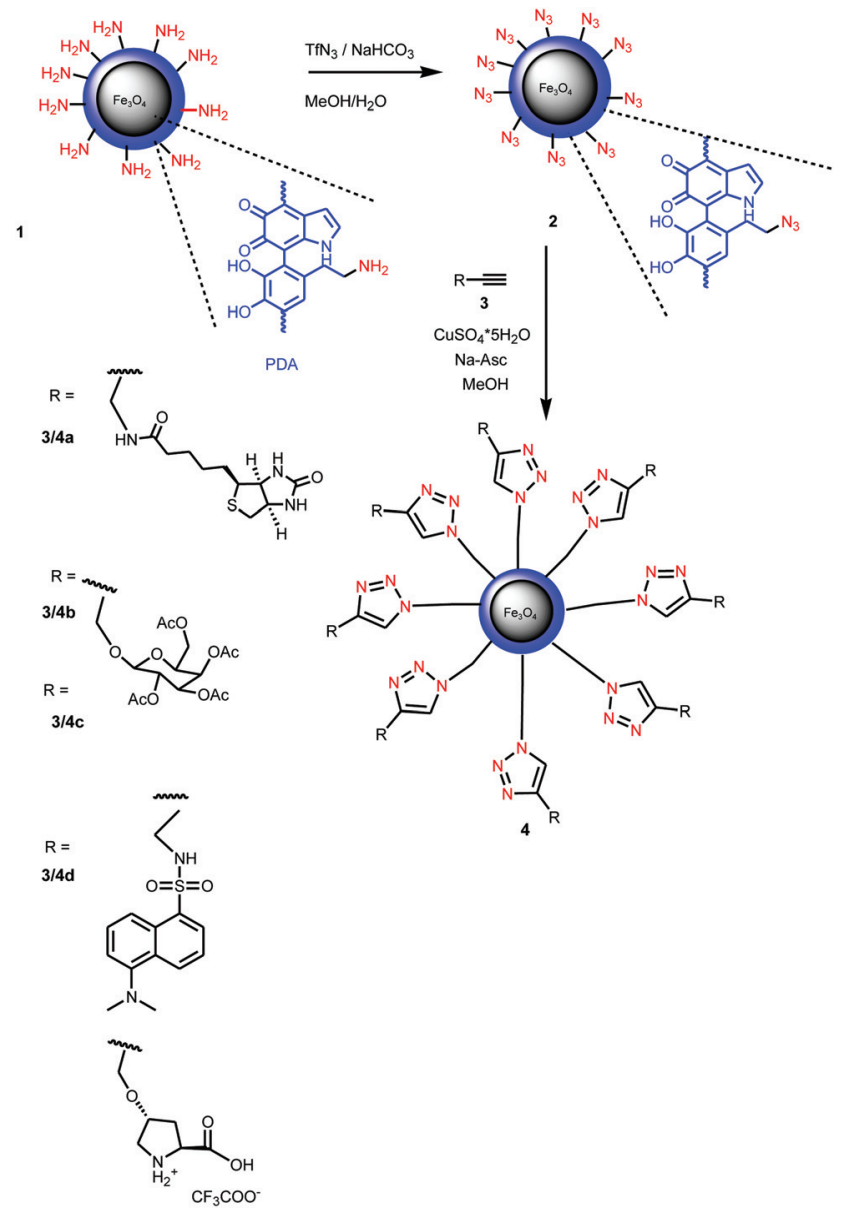

Scheme 1 Diazo transfer at PDA-coated magnetite NP 1 and CuAAC at the resulting azido-functionalized MNP 2 for the introduction of bioentities and dansyl.

the remaining azido groups in MNP 4 do not create problems because they are hardly accessible and chemically inert in most other applications. In the galactose-tetraacetate containing MNP $4 \mathbf{b}$ a $\mathrm{C}=\mathrm{O}$ stretching vibration at $1757 \mathrm{~cm}^{-1}$ and a $\mathrm{C}-\mathrm{O}-\mathrm{C}$ valence band at $1236 \mathrm{~cm}^{-1}$ was observed in the FTIR spectrum, while MNP $4 \mathbf{c}$ exhibit an IR-band at $1370 \mathrm{~cm}^{-1}$ due to the stretching vibration of the sulfonamide group found in dansyl.

TGA of the MNP 2 and $\mathbf{4 b}$ revealed an increase in organic material after the CuAAC which is in agreement with the increase in molecular weight of $\mathbf{4 b}$ (see ESI $\dagger$ ).

The successful introduction of bio-entities was further proved by XPS measurements. Thus the deconvoluted $\mathrm{S} 2 \mathrm{p}$ spectrum of $4 \mathrm{a}$ (Fig. 3) proved the presence of sulphur. It contains a doublet S $2 \mathrm{p}_{3 / 2}-162.9 \mathrm{eV}$ and $\mathrm{S} 2 \mathrm{p}_{1 / 2} 164.5 \mathrm{eV}$ in the ratio $2: 1$ corresponding to the $\mathrm{C}-\mathrm{S}-\mathrm{C}$ moiety of biotin. In addition, another doublet $\mathrm{S} 2 \mathrm{p}_{3 / 2}-167.8 \mathrm{eV}, \mathrm{S} 2 \mathrm{p}_{1 / 2} 169.4 \mathrm{eV}$ is found, which can be explained by a $-\mathrm{C}-\mathrm{SO}_{2}-\mathrm{C}-$ moiety obviously derived from oxidized biotin. It is well known that the oxidation of the biotin moiety occurs easily with different oxidizing reagents such as peroxides under mild conditions and is also observed in biological metabolism of biotin. ${ }^{43}$ 

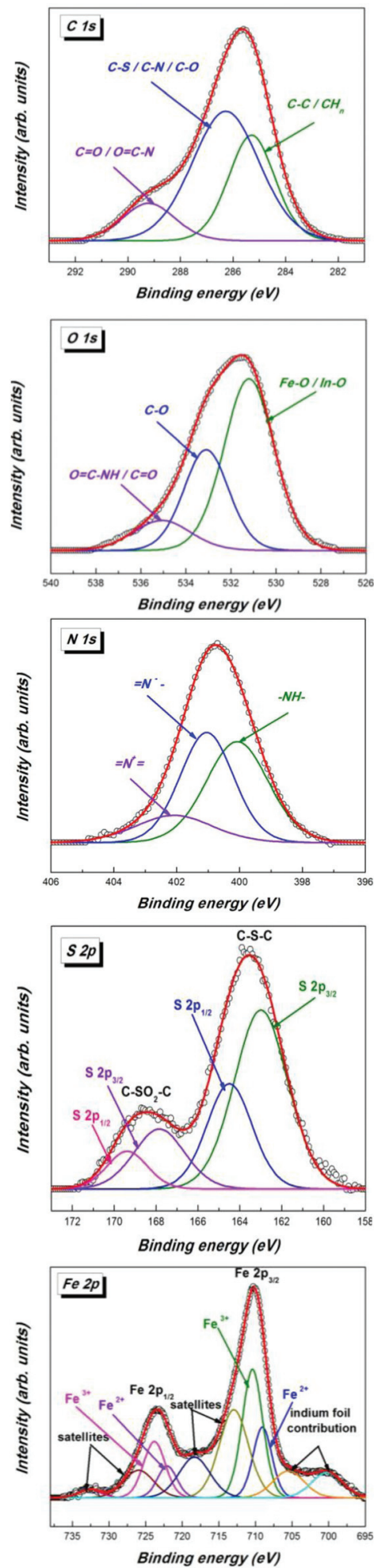

Fig. 3 High resolution XPS spectra of $C 1 s, O$ 1s, N 1s, S $2 p$ and Fe 2p core levels of MNP $4 a$.

The C 1s spectrum can be deconvoluted into three peaks corresponding to carbon atoms from different groups. The higher binding energy component centered at $289.2 \mathrm{eV}$ corresponds to carbon atoms from the $\mathrm{O}-\mathrm{C}=\mathrm{NH} /$
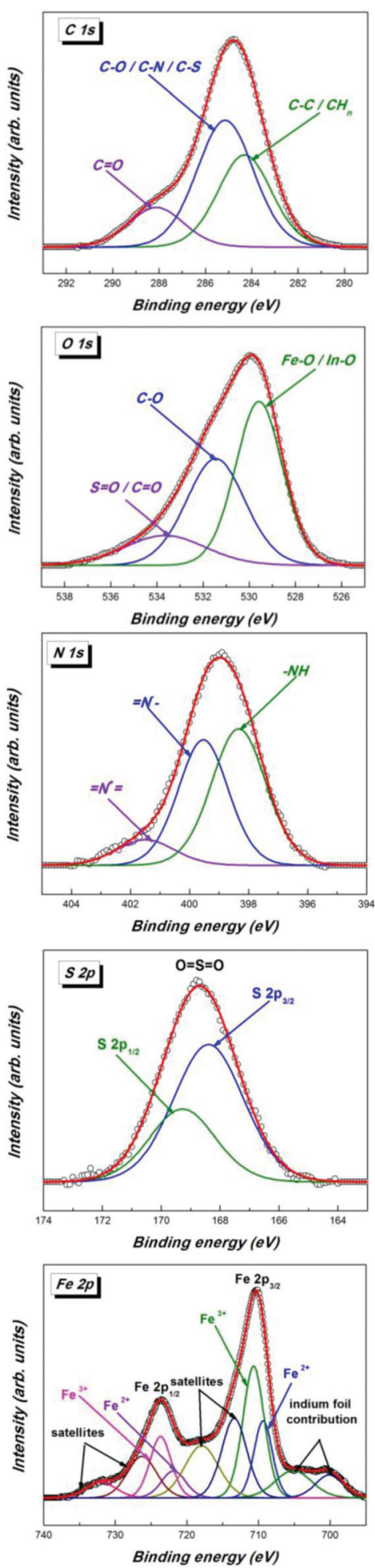

Fig. 4 High resolution XPS spectra of $C 1 s, O 1 s, N 1 s, S 2 p$ and Fe $2 p$ core levels of MNP 4c.

$\mathrm{C}=\mathrm{O}$ groups, the intense component peak located at $286.5 \mathrm{eV}$ is ascribed to carbon atoms from the $\mathrm{C}-\mathrm{S} / \mathrm{C}-\mathrm{N} / \mathrm{C}-\mathrm{O}$ groups, while the component at $285.3 \mathrm{eV}$ corresponds to $\mathrm{C}-\mathrm{C} /$ $\mathrm{CH}_{n}$ groups. 
The $\mathrm{O}$ 1s spectrum exhibits three components assigned to the oxygen atoms of the $\mathrm{C}=\mathrm{O} / \mathrm{O}=\mathrm{C}-\mathrm{NH}$ group (534.4 eV), $\mathrm{C}-\mathrm{O}$ groups $(531.7 \mathrm{eV})$ and to metal oxides, magnetite and oxidized indium support, respectively $\mathrm{Fe}-\mathrm{O} / \mathrm{In}-\mathrm{O}(529.9 \mathrm{eV})$. The $\mathrm{N} 1 \mathrm{~s}$ core-level spectrum shows three components in agreement with the functionalization with biotin and the presence of unmodified azido groups: (i) the component at $399.9 \mathrm{eV}$ corresponds to $-\mathrm{NH}$; (ii) the component located at $401.1 \mathrm{eV}$ is ascribed to the negatively charged terminal nitrogen atom of the azido group $\left(-\mathrm{N}=\mathrm{N}^{+}=\mathrm{N}^{-}\right)$; (iii) the high binding energy component located at $402.1 \mathrm{eV}$ corresponds to a positively charged central nitrogen atom of the azido group $\left(-\mathrm{N}=\mathbf{N}^{+}=\mathrm{N}^{-}\right)$.

The $\mathrm{SO}_{2} \mathrm{~N}$ moiety of the dansyl functionalized MNP $4 \mathrm{c}$ is confirmed by the presence of two components at $2 \mathrm{p}_{3 / 2}$ $(168.4 \mathrm{eV})$ and $2 \mathrm{p}_{1 / 2}(169.3 \mathrm{eV})$ in a ratio of $2: 1$ in the $\mathrm{S} 2 \mathrm{p}$ core-level XPS spectrum (Fig. 4). Again, residual azido groups are found at $399.5 \mathrm{eV}$ and $401.4 \mathrm{eV}$. The best approximations of the $\mathrm{C} 1 \mathrm{~s}$ and $\mathrm{O}$ 1s spectra were obtained with three components described by a Gaussian-Lorentzian product function, with full-width at half maximum (FWHM) smaller than $3.1 \mathrm{eV}$. $\mathrm{C} 1 \mathrm{~s}$ consists of the following peaks: $\mathrm{C}-\mathrm{C} / \mathrm{CH}_{n}$ at $284.3 \mathrm{eV}$, an intense component corresponding to $\mathrm{C}-\mathrm{O} / \mathrm{C}-\mathrm{N} / \mathrm{C}-\mathrm{S}$ at $285.2 \mathrm{eV}$ and the component located in the high binding energy region of the spectra, at $288.1 \mathrm{eV}$, corresponding to the carbon atoms of $\mathrm{C}=\mathrm{O}$ groups. $\mathrm{O}$ 1s was deconvoluted in $\mathrm{FeO} / \mathrm{In}-\mathrm{O}$ (529.6 eV), $\mathrm{C}-\mathrm{O}(531.5 \mathrm{eV})$ and $\mathrm{O}=\mathrm{C} / \mathrm{S}=\mathrm{O}(532.9 \mathrm{eV})$. The spin-orbit coupling gives rise to a doublet of lines in the Fe $2 \mathrm{p}$ high resolution spectrum: $\mathrm{Fe} 2 \mathrm{p}_{3 / 2}(710.4 \mathrm{eV})$ and $\mathrm{Fe} 2 \mathrm{p}_{1 / 2}$ (723.7 eV).

The PDA-coated NP maintained their superparamagnetic properties during the transformation from 2 to $\mathbf{4}$ as can be seen by the magnetic measurements (Fig. 5). The slight decrease in the saturation magnetization values is attributed to the increase in weight as a result of the CuAAC. But they are still high (4a: 45 emu g $^{-1}, \mathbf{4 b}: 39$ emu g $^{-1}, 4$ c: 45 emu g ${ }^{-1}, 4 d$ : $49 \mathrm{emu} \mathrm{g}^{-1}$ ) making the MNP 4 attractive for applications in biology or medicine where localization is necessary under the influence of an external magnetic field.

The functionalized MNP 4 form colloidal suspensions in water where they showed narrow size distributions (Fig. 6). Interestingly, their hydrodynamic diameters $\left(4 \mathbf{a}: D_{\mathrm{h}}=\right.$ $194.6 \mathrm{~nm}, \mathbf{4 b}: D_{\mathrm{h}}=114.1 \mathrm{~nm}, \mathbf{4 c}: D_{\mathrm{h}}=186.2 \mathrm{~nm}, \mathbf{4 d}: D_{\mathrm{h}}=$ $219.5 \mathrm{~nm})$ were smaller than that of their precursor $2\left(D_{\mathrm{h}}=\right.$ $340.7 \mathrm{~nm}$ ). The phenomenon might be caused by partial reduction of the polydopamine under the reaction conditions (formation of $\mathrm{H}$-bond forming phenolic $\mathrm{OH}$ groups from o-quinone units) of the CuAAC (Na-ascorbate as the reducing reagent).

\section{Conclusions}

A novel way of extending the reactivity of PDA coated magnetic nanoparticles to CuAAC was disclosed by applying direct diazo transfer reaction to the amino groups found in PDA. This reac-
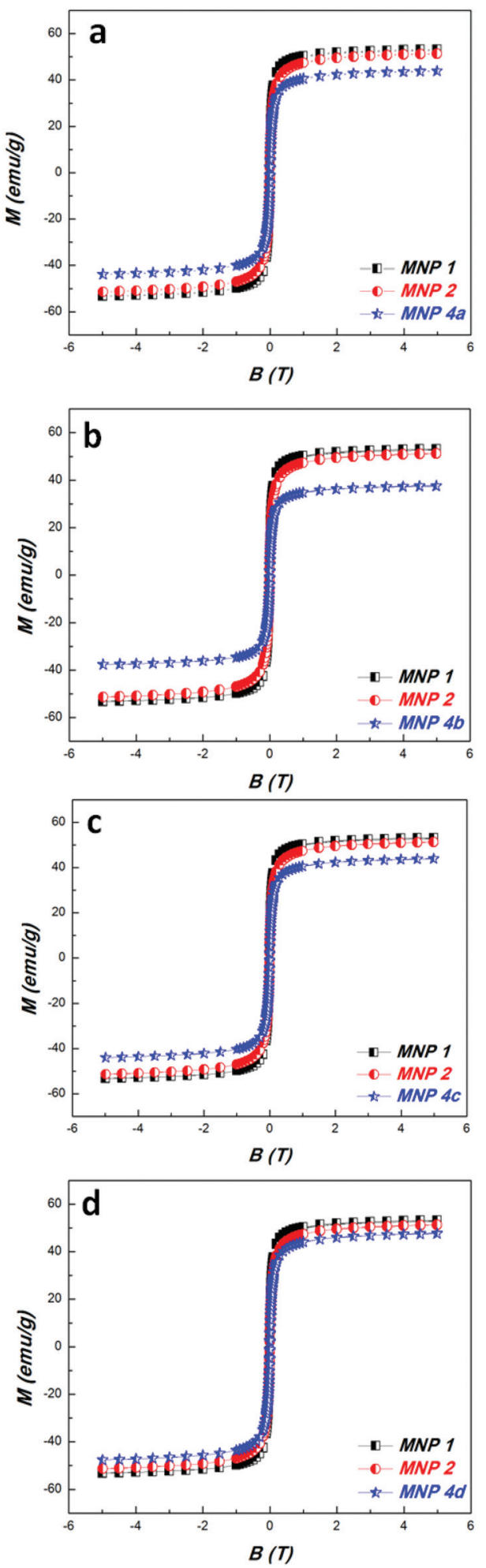

Fig. 5 Magnetic measurements of MNP 1, 2, 4.

tion presents a further experimental proof for the recently verified structural model for PDA. ${ }^{41}$ In this straightforward way azido moieties were introduced on the surface of MNP resulting in a new magnetic nanoplatform. In order to exemplify its 

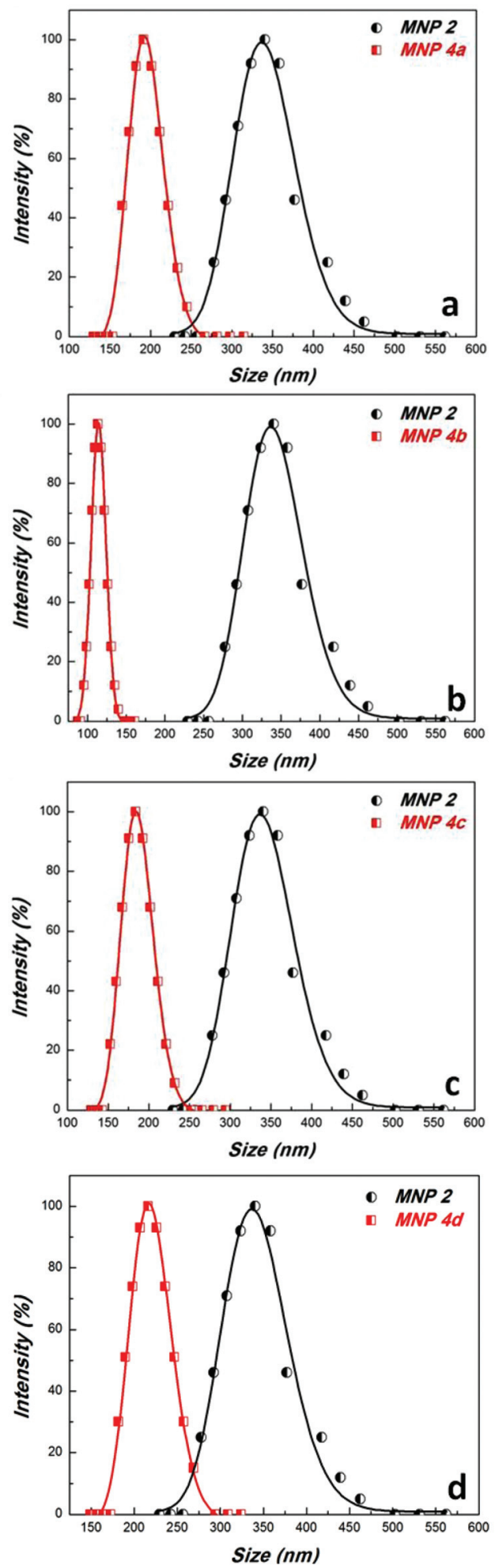

Fig. 6 DLS-measurements of MNP 2 and 4 in water.

utility it was submitted to CuAAC click reaction with alkynecontaining applicatory functions, such as biotin, tetraacetylgalactose, dansyl and proline. The new materials show superparamagnetic behaviour with high values of magnetization, which is essential for applications where direction of the nanoparticles by a magnetic gradient is necessary. It is worth mentioning that this method of diazo transfer does not block quinone functions present in the PDA. Hence, combination of the CuAAC reactivity with Michael and thio-Michael reactions is still possible. This can lead to orthogonal double functionalization of virtually any material covered with PDA and may be useful in preparation of smart materials. Studies of the preparation of such smart materials, employing the dual reactivity of PDA, are presently underway in our laboratory.

\section{Acknowledgements}

This work was supported by the Romanian Ministry of Education and Research under the research program POS-CCEMETAVASINT, project no 550/2010. The authors acknowledge Dr Ioan Bratu for FTIR (INCDTIM Cluj-Napoca) measurements and Dr C. Leostean for assistance in XPS-spectroscopy and magnetic measurements and Dr Lucian Barbu for TEM investigations. We thank Dr Joachim Leistner, Humboldt-University Berlin for TGA.

\section{Notes and references}

1 H. Goesmann and C. Feldmann, Angew. Chem., Int. Ed., 2010, 49, 1362-1395.

2 S. Laurent, D. Forge, M. Port, A. Roch, C. Robic, L. Vander Elst and R. N. Muller, Chem. Rev., 2008, 108, 2064-2110.

3 A.-H. Lu, E. L. Salabas and F. Schüth, Angew. Chem., Int. Ed., 2007, 46, 1222-1244.

4 T. Perrier, P. Saulnier and J.-P. Benoît, Chem. - Eur. J., 2010, 16, 11516-11529.

5 A. Figuerola, R. Di Corato, L. Manna and T. Pellegrino, Pharmacol. Res., 2010, 62, 126-143.

6 M. Arruebo, R. Fernández-Pacheco, M. R. Ibarra and J. Santamaría, Nano Today, 2007, 2, 22-32.

7 W. H. De Jong and P. J. Borm, Int. J. Nanomed., 2008, 3, 133-149.

8 L. Josephson, in BioMEMS and Biomed. Nanotechn, ed. M. Ferrari, A. Lee and L. J. Lee, Springer US, Editon edn, 2006, pp. 227-237.

9 S. Shylesh, V. Schünemann and W. R. Thiel, Angew. Chem., Int. Ed., 2010, 49, 3428-3459.

10 R. Mrowczynski, A. Nan and J. Liebscher, Rsc Adv., 2014, 4, 5927-5952.

11 Z. Yacob, A. Nan and J. Liebscher, Adv. Synth. Catal., 2012, 354, 3259-3264.

12 R. A. Sperling and W. J. Parak, Philos. Trans. R. Soc. A: Math., Phys. Eng. Sci., 2010, 368, 1333-1383.

13 A. S. Teja and P.-Y. Koh, Prog. Cryst. Growth Charact. Mater., 2009, 55, 22-45.

14 S. L. Easo and P. V. Mohanan, Carbohydr. Polym., 2013, 92, 726-732. 
15 N. W. Bolden, V. K. Rangari, S. Jeelani, S. Boyoglu and S. R. Singh, J. Nanopart., 2013, 2013, 9.

16 S. Karsten, A. Nan, R. Turcu and J. Liebscher, J. Polym. Sci., Part A: Polym. Chem., 2012, 50, 3986-3995.

17 C. Socaci, M. Rybka, L. Magerusan, A. Nan, R. Turcu and J. Liebscher, J. Nanopart. Res., 2013, 15, 1-14.

18 T. D. Schladt, K. Schneider, H. Schild and W. Tremel, Dalton Trans., 2011, 40, 6315-6343.

19 R. Mrówczyński, L. Rednic, R. Turcu and J. Liebscher, J. Nanopart. Res., 2012, 14, 1-11.

20 M. Das, D. Bandyopadhyay, D. Mishra, S. Datir, P. Dhak, S. Jain, T. K. Maiti, A. Basak and P. Pramanik, Bioconjugate Chem., 2011, 22, 1181-1193.

21 N. Li and W. H. Binder, J. Mater. Chem., 2011, 21, 16717-16734.

22 T. T. T. N'Guyen, H. T. T. Duong, J. Basuki, V. Montembault, S. Pascual, C. Guibert, J. Fresnais, C. Boyer, M. R. Whittaker, T. P. Davis and L. Fontaine, Angew. Chem., Int. Ed., 2013, 52, 14152-14156.

23 W. R. Algar, D. E. Prasuhn, M. H. Stewart, T. L. Jennings, J. B. Blanco-Canosa, P. E. Dawson and I. L. Medintz, Bioconjugate Chem., 2011, 22, 825-858.

24 L. Polito, D. Monti, E. Caneva, E. Delnevo, G. Russo and D. Prosperi, Chem. Commun., 2008, 621-623.

25 L. Russo, S. Zanini, C. Riccardi, F. Nicotra and L. Cipolla, Mater. Today, 2011, 14, 164-169.

26 Y. Liu, K. Ai and L. Lu, Chem. Rev., 2014, 114, 5057-5151.

27 M. E. Lynge, R. van der Westen, A. Postma and B. Stadler, Nanoscale, 2011, 3, 4916-4928.

28 H. Lee, S. M. Dellatore, W. M. Miller and P. B. Messersmith, Science, 2007, 318, 426-430.
29 R. Liu, Y. Guo, G. Odusote, F. Qu and R. D. Priestley, ACS Appl. Mater. Interfaces, 2013, 5, 9167-9171.

30 C.-Y. Chien and W.-B. Tsai, ACS Appl. Mater. Interfaces, 2013, 5, 6975-6983.

31 X. Liu, J. Cao, H. Li, J. Li, Q. Jin, K. Ren and J. Ji, Acs Nano, 2013, 7, 9384-9395.

32 T. Shalev, A. Gopin, M. Bauer, R. W. Stark and S. Rahimipour, J. Mater. Chem., 2012, 22, 2026-2032.

33 Y. Wang, S. Wang, H. Niu, Y. Ma, T. Zeng, Y. Cai and Z. Meng, J. Chromatogr., A, 2013, 1283, 20-26.

34 X. Yu, M. Wei and J. Walsh, Rsc Adv., 2014, 4, 7185-7192.

35 J. Cui, Y. Yan, G. K. Such, K. Liang, C. J. Ochs, A. Postma and F. Caruso, Biomacromolecules, 2012, 13, 2225-2228.

36 H. Gao, Y. Sun, J. Zhou, R. Xu and H. Duan, ACS Appl. Mater. Interfaces, 2012, 5, 425-432.

37 M. Zhang, X. Zhang, X. He, L. Chen and Y. Zhang, Nanoscale, 2012, 4, 3141-3147.

38 R. Mrówczyński, R. Turcu, C. Leostean, H. A. Scheidt and J. Liebscher, Mater. Chem. Phys., 2013, 138, 295-302.

39 R. Luo, L. Tang, J. Wang, Y. Zhao, Q. Tu, Y. Weng, R. Shen and N. Huang, Colloids Surf., B: Biointerfaces, 2013, 106, 66-73.

40 Q. Wei, B. Li, N. Yi, B. Su, Z. Yin, F. Zhang, J. Li and C. Zhao, J. Biomed. Mater. Res., 2011, 96, 38-45.

41 J. Liebscher, R. Mrówczyński, H. A. Scheidt, C. Filip, N. D. Hădade, R. Turcu, A. Bende and S. Beck, Langmuir, 2013, 29, 10539-10548.

42 A. Titz, Z. Radic, O. Schwardt and B. Ernst, Tetrahedron Lett., 2006, 47, 2383-2385.

43 D. B. Melville, J. Biol. Chem., 1954, 208, 495-501. 